\title{
Rational Emotive Therapy Workshop
}

\author{
Hugh Freeman, Editor, British Journal of Psychiatry
}

Last year, I was very fortunate to be able to attend a workshop at Sheffield University on Rational Emotive Therapy - fortunate because Dr Albert Ellis of New York, who conducted it and who founded RET, is surely one of the most remarkable figures on the international scene in psychiatry. His presentation is frankly dramatic, but he insists that far from being undesirable, this quality may be essential in transmitting a therapeutic message to the patient.

Dr Ellis says that RET began in the mid 1950s, when he came to the conclusion that because psycho-analysis concerned itself with every form of irrelevancy, it was in the end only superficial and ineffective. He was unconvinced that early childhood is responsible for most emotional disturbances. Instead, he went back to the stoic philosophers and followed their view that since we feel the way we think, we must overcome incorrect thinking through changes in the way we feel and act. This approach was combined in an eclectic way with some of the cognitive aspects of behavioural therapy and with a direct approach to emotional change, though in practice, all of them are inextricably mixed up.

Ellis defines three main strands in the personality: A consists of goals, desires, purposes, values, and interests; $B$ is the belief system, which when irrational, tends to block and control A; $C$ consists of disturbed feelings such as sorrow, regret, frustration, inappropriate depression, despair, and annoyance. When the relationships between the elements are dysfunctional, there may be behavioural disturbance (e.g. phobic or compulsive) or feeling states which are maladaptive to that individual or to society. However, if B can be changed from irrational to rational, then $\mathrm{C}$ is minimised and $\mathrm{A}$ is more likely to be realised. The difference from other cognitive theories is that B is divided into rational (preferences, goals, wishes) and irrational (inferences, misperceptions, absolutistic demands). Emotional disturbance results when B is irrational, rather than rational, and A may then be altered adversely, so that one is depressed about depression or anxious about panics.

Ellis sees irrational beliefs taking over when the element of 'must' enters thinking - e.g. 'I must do well and be approved of by others, or I am no good and will feel shame, guilt, anxiety'; 'The person with whom I interact must treat me kindly and considerately, or I will not be able to bear her (him) and will feel anger, hostility, rage'; 'Society must provide the kind of conditions that I want, or I will regard it as no good and feel intolerant, depressed, frustrated.' All such ideas are grandiose; for instance, no person can realistically expect to be ever loved by more than 10 or 12 others.

The implication of this, in Ellis' scheme, is that the therapist should not try to interfere with the patient's basic values, but dispute the irrational beliefs and hypotheses cognitively. This is done, firstly by asking such questions as - why should your demands be met? Secondly, a number of basic insights need to be taught: (a) You mainly create your own disturbance, e.g. through 'musts' and 'oughts'; (b) However it started, you are continuing the process now, e.g. by making irrational demands; (c) False beliefs can only be overcome by work and practice. Thirdly, merely promoting self-esteem is unhelpful, since any failure to do well in the world will then bring back negative perceptions of the self. Instead, the self or ego should not be rated at all-only the individual's acts or performances.

Ellis says that RET consists of three basic techniques, which overlap with each other. Firstly, there is a variety of cognitive methods, designed to destroy imperatives and over-generalisations; examples of these are imaging (to undermine negative perceptions), reframing (to see the bad as a challenge), cognitive homework, debates between patients, distraction from anxiety (relaxation, yoga), modelling, philosophy (teaching acceptance of the self and others as less than perfect), humour (to destroy absurd thinking), semantic discussion, and problemsolving. Secondly, there are specific rational-emotive methods-(a) Challenging - Why must you do well?' 'What is the worst thing that could happen'? (b) Shame-attacking exercises. (c) Listing one's pleasures. Thirdly, behavioural methods such as in vivo desensitisation, or reinforcement.

So as far as the relationship between thoughts and feelings are concerned, Ellis suggests that most patients actually have few hidden feelings, but many that are conscious. Intervention therefore requires discussion of these in relation to the ABC model, showing the patient what he/she has done to create those feelings, but emphasising that he/she is still acceptable as a person, even with that feeling or hatred. The distinction is emphasised between the hostile action and the person who carries it out.

Ellis accepts that every society lays down standards and ethics, but challenges the feelings of selfworthlessness which often follow if an individual departs from those in any way. He seeks to show the 
difference between 'I want', which is within reality, and 'I must', which is not. In respect of health, he challenges hypochrondriasis by pointing out to those who demand the certainty of good health that there is no such thing as certainty in the Universe. He is not against anger, since justifiable anger is necessary for social change, but challenges that enraging against oneself which destroys efficiency of action. He encourages the expression of feelings (e.g. by encounter techniques), if they are appropriate, since this may allow more justifiable risks to be taken.

After his exposition of RET in the workshop, Ellis took three volunteers from the audience who wished to consult him about a personal problem. To the first, who complained of regularly waking up feeling depressed, he said - "You feel you don't deserve to feel uncomfortable about that feeling, but does the universe care? Why shouldn't it be the way it is? Why should you feel better? Where will your belief (that you shouldn't feel like this) get you? You'll only feel more depressed. The belief needs to be changed to a preference. Give up the 'must', the command, but not the value. If the original depression can be accepted, it can be confronted. What are you telling yourself on waking? That 'things shouldn't be harder than I want them to be'? That 'I can accept so much hardness, but no more'? You don't run the universe. Your low frustration tolerance makes things more frustrating, and harder for you. Why is it so terrible if you fail? (The volunteer mentioned fear of professional failure). Close your eyes - imagine the worst things that could happen - how do you feel in your gut? What would you call that churned-up feeling? Make yourself as anxious as possible. Are you in touch with that feeling? Change that feeling now. Feel only sorry and disappointed, but not anxious and depressed." Ellis then advised shame-attacking exercises and the use of music as a reward, after practising appropriate imagery.

The next volunteer said his wife had left him, after 22 years, and was intending to marry his brother. Ellis said "What did you tell yourself about her? Why must she not be wrong? Why shouldn't your brother have acted badly? If you accept that they behaved wrongly, you'll lose your anger. As a fallible human, haven't you the right to do wrong? Ask yourself Why am I punishing myself? You demand that your behaviour was so perfect that she could never have done wrong? You demand that if you do the right thing, they mustn't do the wrong thing, but in fact, humans often do the wrong thing." Ellis continued
"If you accepted that reality, you would still feel sad, but not feel hatred. How do you know you will never forgive them? You can forgive them, but still think they were wrong. (The volunteer was advised to write down sentences along these lines). 'Imagine that you meet them and they laugh at you. How do you feel then? Change the feeling to just being displeased and sorry, but not hurt. Have there been such situations in the past where you later forgave the people. You're clinging to your anger; when you're angry with people, you feel above them. Unfortunately, people will do what they do." Ellis advised the volunteer to undertake homework exercises, to repeat tape recordings of the session, and not to avoid his ex-wife and brother.

The third volunteer complained of the problem of procrastination. Ellis described this as substituting short-range hedonism for long-range. He said "What do you tell yourself about it? How do you exercise yourself for not doing what you can do? Do you believe you should only have to do what you like, when you want to, because of low frustration tolerance? If you say to yourself that you're stupid for not getting on with it, that's an error-you're putting yourself down and stopping yourself from behaving differently. It's your actions that are stupid. What are you saying that stops you from doing it, at the last moment? 'I shouldn't have to do it - it should do it itself? Many procrastinators are perfectionists. Say to yourself - 'It's harder if I don't do it.' Imagine a very hard assignment-get in touch with your protesting feeling - change that to feeling sad, sorry, and disappointed, but not protesting or giving up. Relaxation is a preliminary step to getting to the appropriate feeling. The issue is childish rebelliousness.'

These passages may give some of the flavour of a day-long workshop conducted by Dr Ellis, now in his late seventies, with enormous vigour and panache - it included leading the audience in community singing or parodies which illustrated RET themes. Rational Emotive Therapy seems to offer a practical approach to many emotional and personality problems, accepting that to be able to feel less anxious or depressed or worried than one did is better than no change at all. The extracts given here may give the impression that RET is a 'tough' therapy, perhaps too abrasive and challenging for real patients, but that is not the experience of some therapists who were present. In everyday practice, RET would tend to be applied at a more gentle pace than that used by Dr Ellis for his demonstration. 